\title{
Análise espacial da taxa de alfabetização e sua relação com os aspectos socioeconômicos nos municípios paranaenses
}

\author{
Spatial analysis of the literacy rate and its relationship with socioeconomic aspects in \\ Paraná municipalities
}

\author{
Renan Henrique Luquini', Gustavo Henrique Leite de Castro", José Luiz ParrélII
}

\begin{abstract}
Resumo
O presente estudo tem como objetivo analisar espacialmente a alfabetização nos municípios do estado do Paraná sob a óptica socioeconômica por meio de três variáveis: renda média, índice de Gini e grau de urbanização. Para isso, a base de dados utilizada foi malha georeferênciada do Paraná (shapefile) disponível no Instituto Paranaense de Desenvolvimento Econômico e Social - IPARDES, e dados referentes ao Censo demográfico do ano de 2010 para os municípios paranaenses. Os resultados encontrados para a região evidenciam que os valores a partir do modelo econométrico espacial SEM se mostraram superiores ao MQO e mostram que quanto menor é o Índice de Gini e maior a Renda Média e a Urbanização, maior é a taxa de alfabetização nos municípios paranaenses. Observa-se a necessidade de políticas com o intuito de uma melhor distribuição de renda territorial.
\end{abstract}

Palavras-chave: Econometria Espacial; Taxa de Alfabetização; Paraná

\begin{abstract}
The present study aims at analyzing spatially literacy in the municipalities of the state of Paraná under the socioeconomic perspective through three variables: mean income, Gini index and degree of urbanization. For this, the database used was georeferenced from Paraná (shapefile) available at the Paraná Institute of Economic and Social Development - IPARDES, and data referring to the demographic census of the year 2010 for the municipalities of Paraná. The results found for the region show that the values from the spatial econometric model SEM were higher than the OLS and they show that the lower the Gini Index and the higher the Average Income and Urbanization, the higher is the literacy rate in the municipalities of Paraná. It is observed the need for policies with the aim of a better distribution of territorial income.
\end{abstract}

Keywords: Spatial Econometrics; Literacy Rate; Paraná

\footnotetext{
' Mestre em Economia Regional pela Universidade Estadual de Londrina

"Mestre em Economia Regional pela Universidade Estadual de Londrina

III Professor Estadual de Maringá na Universidade Estadual de Maringá
} 


\section{Introdução}

A alfabetização tem sido tema relevante de estudos científicos na sociedade brasileira, podendo ser classificada como o alicerce principal para o desenvolvimento econômico sustentável de uma nação, além de uma condição essencial para a redução da pobreza e para o progresso social e cultural de um país. Importante destacar que a educação e o desenvolvimento estão intrinsecamente associados no que concerne à formação dos indivíduos, ou seja, um maior nível de educação pode aumentar o nível de renda de um país. Contudo, as desigualdades ainda são imensas no Brasil e suas regiões e por isso o país ainda acumula atrasos significativos nessa área.

Fazendo uma análise regional, observando mais especificamente o estado do Paraná, percebe-se que por mais que existam certas condições favoráveis, também são verificadas carências socioeconômicas importantes que impactam negativamente na população e especificamente nos índices de alfabetização. Sendo assim, verifica-se a necessidade não somente de boas escolas, mas também que a região a qual elas se encontrem propicie condições satisfatórias econômicas e sociais aos alunos. Diante do exposto, o presente estudo tem como objetivo analisar espacialmente a alfabetização nos municípios do estado do Paraná sob a óptica socioeconômica por meio de três variáveis: Renda Média, Índice de Gini e Grau de Urbanização.

Localizado na região Sul do Brasil, o estado do Paraná (objeto do presente estudo) faz fronteira com a Argentina e o Paraguai e divisas com os estados de São Paulo, Mato Grosso do Sul e Santa Catarina. De acordo com IPARDES (2016) no ano de 2013 o Paraná representou 6,3\% do PIB nacional, o que faz do estado a quarta maior economia do país, possuindo também uma renda per capita de $\mathrm{R} \$ 30,3$ mil, superior ao pib per capita nacional de $\mathrm{R} \$ 26,4$ mil. Os setores produtivos estão distribuídos por todo estado sendo os municípios de Londrina, Maringá e Ponta Grossa representantes dos setores agroindustrial e de serviços. Já a capital Curitiba e São José dos Pinhais concentram os setores de industriais e os setores de serviços, sendo estes com maiores representatividades no PIB estadual.

A justificativa para a realização do estudo se dá, tanto na importância do entendimento das questões socioeconômicas, como também em verificar como as mesmas impactam na alfabetização paranaense. Destaca-se que são poucos os estudos sobre essa temática tais como: IPARDES (2003); IPARDES (2004); Silva et al. (2006); Michon Júnior (2008) e Vidigal et al. (2012). Outro ponto importante é a temática da pesquisa é pouco explorada pelos estudos supracitados e os seus enfoques tem-se pautado nos determinantes e nas mudanças socioeconômicas do estado no decorrer dos anos. Assim, portanto, percebe-se uma certa ausência de estudos que relacionam os aspectos sociais e econômicos com a alfabetização para o estado do Paraná, sendo que, dessa forma, o presente estudo apresenta pioneirismo quanto ao seu objetivo. A pesquisa tem, dessa forma, o intuito de fornecer o entendimento da seguinte questão: qual a influência espacial das variáveis socioeconômicas no comportamento da alfabetização paranaense?

$\mathrm{Na}$ esperança de se atingir o objetivo proposto, o presente estudo se divide em cinco seções contando com esta introdução. Na seção dois encontra-se o referencial teórico e empírico. Na terceira seção encontram-se os procedimentos metodológicos onde se apresentam a base de dados, como se dá a análise exploratória dos mesmos, os principais modelos econométricos espaciais e, por fim, o modelo econométrico espacial utilizado. Já na quarta seção, são apresentados os resultados para os municípios paranaenses. Na quinta seção, encontram-se as considerações finais.

\section{Características da alfabetização e aspectos socioeconômicos do estado do Paraná}

A preocupação com a educação vem sendo abordada por diversos pesquisadores, especialmente no Brasil, cujas características continentais e desigualdades regionais e de renda são significativas. A educação, como direito fundamental de todos é dever do Estado e da família, sendo assim, o alicerce para o desenvolvimento sustentável e condição essencial para a redução da pobreza e para o progresso social e cultural de um país. Individualmente, a educação promove o desenvolvimento da pessoa, seu preparo para o exercício da cidadania e sua qualificação para o trabalho. Contudo, as desigualdades ainda são imensas no Brasil e em suas regiões e, dessa maneira, o país ainda acumula atrasos significativos.

Do ponto de vista macroeconômico, Schultz (1961) relaciona a importância dos investimentos em capital humano para o crescimento econômico de um país. Para ele, principalmente em nações pobres (economias em desenvolvimento), o crescimento econômico não é apenas decorrente do investimento em capital de produção, infraestrutura, e outros, mas também do investimento em capital humano. O autor defende a intervenção do estado por meio de leis fiscais e bancárias que promovam os empréstimos privado e público de longo prazo para os estudantes e insiste que grande parte dos baixos rendimentos dos negros, trabalhadores rurais e dos indivíduos mais velhos seria reflexo da falta de investimento do Estado em saúde e educação. Becker (2008) reforça essa ideia e acrescenta que o crescimento contínuo da renda per capita de muitos países durante o século XIX e XX é, em parte, devido à expansão do conhecimento científico e técnico, que aumenta a produtividade do trabalho e o crescimento da nação.

Diversos são os estudos que tem como objetivo estudar e avaliar a educação no país. A pesquisa de Barros et 
al. (2001) tem como o objetivo investigar os determinantes do fraco desempenho educacional brasileiro. Dentre os principais resultados, destaca-se que, na medida em que a escolaridade dos pais é um fator predominante na determinação do nível de escolaridade dos filhos, crianças cujos pais tenham baixa escolaridade possuem grandes chances de tornar-se adultos com pouca escolaridade. Além disso, como a escolaridade é também um fator importante na determinação da renda, caracteriza-se assim uma situação na qual prevalece a desigualdade de oportunidades e, por conseguinte, a transmissão inter geracional da pobreza. Os resultados deste estudo mostram que políticas públicas seriam provavelmente mais efetivas se tivessem como alvo principal as famílias com pais de baixa escolaridade ao invés de baixa renda domiciliar per capita.

Menezes-Filho (2007), por sua vez, busca identificar os determinantes do desempenho escolar do Brasil. O autor conclui que as variáveis que mais explicam o desempenho escolar são as características familiares e do aluno, tais como educação da mãe, cor, atraso escolar e reprovação prévia, número de livros, presença de computador em casa e trabalho fora de casa. Uma variável importante é a idade de entrada no sistema escolar: os alunos que fizeram pré-escola têm um desempenho melhor em todas as séries do que os que entraram a partir da 1ª série. Isto indica que investimentos públicos na infância têm chances maiores de terem sucesso. Uma das únicas variáveis da escola que afetam consistentemente o desempenho do aluno é o número de horas-aula, ou seja, o tempo que o aluno permanece na escola. O autor propõe uma política educacional de aumentar o número de horas-aula, mesmo que para isto seja necessário aumentar o número de alunos por classe, uma vez que seus resultados também mostram que o tamanho da turma não parece afetar o desempenho do aluno em nenhuma série.

Já Felício e Fernandes (2005) analisaram o efeito da qualidade da escola sobre o desempenho escolar. Os autores destacam que nos estudos sobre a relação entre a qualidade da escola e o desempenho escolar, encontra-se uma grande variedade de resultados, mas, de modo geral, o impacto da escola é de relevância pequena especialmente quando comparada à parcela explicada pelo background familiar. Os autores concluem que políticas educacionais e de investimento em educação (qualitativa) podem gerar avanços significativos no desempenho escolar.

No Brasil a taxa de analfabetismo caiu de $1 / 4$ da população para $1 / 5$ no período posterior a 1991 . A tabela 1 mostra a taxa de analfabetismo das pessoas de 10 anos ou mais de idade, de acordo com as grandes regiões para os anos de 2000 e 2010. Observa-se que as regiões Sul e Sudeste possuem as menores taxas para ambos os anos, no sentido contrário as regiões Nordeste e Norte possuem as mais elevadas taxas de analfabetismo. Outro ponto interessante é que mesmo possuindo as menores taxas a região Sul também apresenta a maior variação negativa entre os períodos $(-32,9 \%)$. Outro destaque também é a região Norte com a segunda maior variação negativa $(32,1 \%)$.

Tabela 1- Taxa de analfabetismo das pessoas de 10 anos ou mais de idade, segundo as Grandes Regiões - 2000/2010

\begin{tabular}{lccc}
\hline & $\mathbf{2 0 0 0}$ & $\mathbf{2 0 1 0}$ & $\boldsymbol{\Delta} \%$ \\
\hline Brasil & 12,8 & 9 & $-29,7 \%$ \\
Norte & 15,6 & 10,6 & $-32,1 \%$ \\
Nordeste & 24,7 & 17,6 & $-28,7 \%$ \\
Sudeste & 7,5 & 5,1 & $-32,0 \%$ \\
Sul & 7 & 4,7 & $-32,9 \%$ \\
Centro-Oeste & 9,7 & 6,6 & $-32,0 \%$ \\
\hline
\end{tabular}

Fonte: elaborado pelos autores com base nos dados do IBGE (2017)

Segundo Balassiano (2005), o aumento da escolaridade da população representa que esta adquiriu novos conhecimentos e habilidades via educação formal e, teoricamente, conseguirá extrair mais resultados do seu trabalho, gerando uma maior produtividade e resultando em uma maior produção econômica. O problema é que mesmo que a escolaridade média da população tenha crescido no Brasil de forma constante desde o século passado, a produtividade do trabalhador brasileiro é baixa em relação aos países emergentes.

Já a tabela 2, para os anos 2007 a 2015, mostra a distribuição da taxa de analfabetismo entre as mulheres e os homens com 15 anos ou mais. É possível observar que as mulheres possuem as menores taxas de analfabetismo em relação aos homens e, também, a maior média de variação percentual negativa entre os anos analisados com $-3,45$ \%. Já os homens possuem uma média de variação percentual de $-3,11 \%$. 
Tabela 2 - Taxa de analfabetismo das pessoas de 15 anos ou mais de idade, por sexo - Brasil - 2007/2015

\begin{tabular}{lcccc}
\hline \multirow{2}{*}{ Ano } & \multicolumn{2}{c}{ Homens } & \multicolumn{2}{c}{ Mulheres } \\
\cline { 2 - 5 } & Taxa & $\boldsymbol{\Delta} \%$ & Taxa & $\boldsymbol{\Delta} \%$ \\
\hline 2007 & 10,4 & - & 9,9 & - \\
2008 & 10,2 & $-1,92 \%$ & 9,8 & $-1,01 \%$ \\
2009 & 9,8 & $-3,92 \%$ & 9,6 & $-2,04 \%$ \\
2011 & 8,8 & $-10,20 \%$ & 8,4 & $-12,50 \%$ \\
2012 & 9 & $2,27 \%$ & 8,4 & $0,00 \%$ \\
2013 & 8,8 & $-2,22 \%$ & 8,2 & $-2,38 \%$ \\
2014 & 8,6 & $-2,27 \%$ & 7,9 & $-3,66 \%$ \\
2015 & 8,3 & $-3,49 \%$ & 7,7 & $-2,53 \%$ \\
\hline$\Delta \%$ média & - & $-3,11 \%$ & - & $-3,45 \%$ \\
\hline
\end{tabular}

Fonte: elaborado pelos autores com base nos dados do IBGE (2017)

Nota: o ano de 2010 se encontra na PNAD

No Brasil, assim como em outros países menos desenvolvidos, a educação é frequentemente apontada como a maior fonte da desigualdade. Menezes-Filho (2001), por exemplo, mostra que a distribuição da educação e seus retornos explicam cerca de $40 \%$ da distribuição dos salários no país. Quase metade da desigualdade em remuneração do trabalho decorre de diferenças em capital humano entre trabalhadores brasileiros ${ }^{1}$. Uma importante parcela da recente queda na desigualdade está de fato associada às melhorias no capital humano da força de trabalho e, em particular, às reduções nos diferenciais de remuneração por nível educacional. Entretanto, os mesmos estudos também revelam que apenas metade da queda é explicada por essas mudanças.

De acordo com Barros e Santos (2018), para que exista igualdade de oportunidades é importante garantir condições mínimas para que seja possível a sua utilização e que todos possam se beneficiar integralmente dos serviços oferecidos, ou seja, além de boas escolas para receber os alunos é necessário também que elas tenham as condições socioeconômicas necessárias que lhes possibilitem um aprendizado de qualidade. O autor ainda argumenta que a evidência empírica disponível destaca a importância de programas de transferência de renda que possibilitem aos alunos mais pobres as condições mínimas de que necessitam para frequentar a escola e dela efetivamente se beneficiar. Por outro lado, a evidência também argumenta sobre a necessidade das comunidades escolares e secretarias de educação garantirem os recursos para uma oferta subsidiada, ao menos aos alunos mais pobres, de bens e serviços básicos complementares a educação.

Figura 1 - Distribuição da alfabetização de crianças de 5 e 7 anos no Brasil em 2000 a 2010

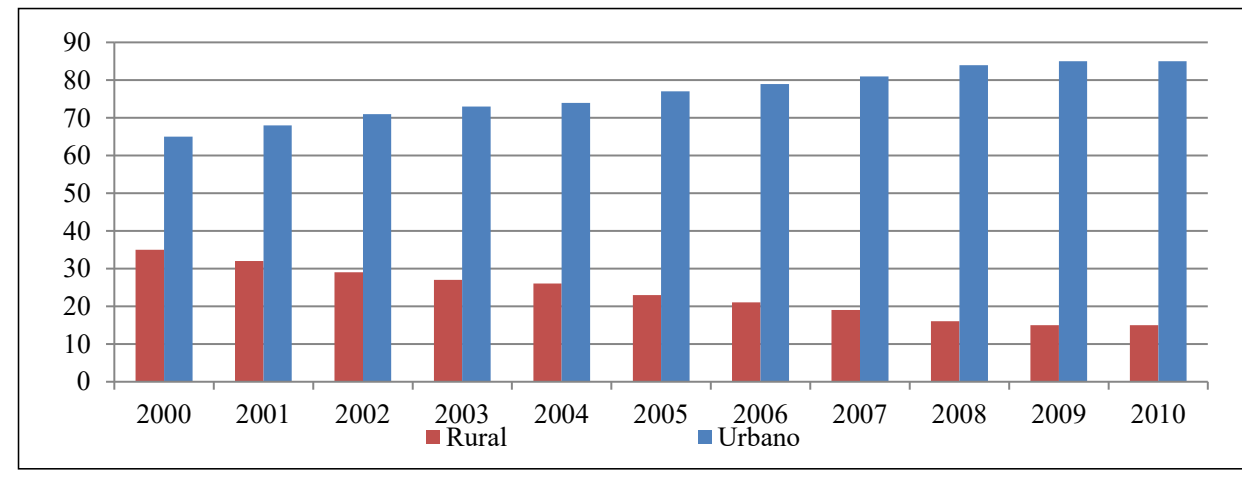

Fonte: elaborado pelos autores com base nos dados da PNAD (2016)

1 Ver: BARROS; FRANCO; MENDONÇA, 2006; FOGUEL; AZEVEDO, 2006; MENEZES-FILHO; FERNANDES; PICCHETTI, 2006a, b; RAMOS, 2006. 
De acordo Cunha (1975), a alimentação, o ambiente domiciliar, a participação da família, entre outros, são fatores determinantes na vida estudantil de uma criança e quando as mesmas são debilitadas pela condição social da família o resultado é percebido em indicadores de educação. Outro fator a ser considerado é a comparação da sociedade rural e urbana através distribuição de estudante de 5 anos e taxa de analfabetos com 7 anos de idades e demonstra que a urbanização e a alfabetização tiveram relação crescente. Sandroni (1994) aponta que cada região depende do seu passado histórico, da sua posição e extensão geográfica, das condições demográficas, da cultura, dos recursos naturais que possuem e da relação política de fomento a variáveis socioeconômicas importantes como: distribuição de renda, pobreza, alfabetização e outras medidas de soluções sociais.

Consoante a essas informações, vários são os estudos que destacam as reflexões sobre os indicadores socioeconômicos do estado do Paraná, como, por exemplo, as pesquisas de Silva e Michon Júnior (2008), que descrevem as mudanças socioeconômicas e territoriais a partir das transformações produtivas do Paraná e das suas mesorregiões na década de 1990. Os resultados apontam que os ganhos foram concentrados na região metropolitana, mas foi uma década com forte melhora em vários indicadores (distribuição de renda, saúde e educação). A justificativa se dá pelo maior grau de urbanização e pela demanda por mão de obra qualificada sendo que ambos melhoraram a educação da população. Além disso, a criação de novas universidades no estado e a alteração do sistema educacional do ensino fundamental reduziram a evasão escolar e aumentando a quantidade média de anos de estudos da população adulta.

Apesar da tendência do estado em mostrar melhoria nos indicadores os resultados entre as mesorregiões diferem, como mostram os estudos de Vidigal et al. (2012), os quais buscaram avaliar as diferenças de nível de desenvolvimento socioeconômico entre as microrregiões do Estado do Paraná, bem como hierarquizá-las e agrupá-las de acordo com suas características. Os principais resultados mostraram que, apesar de se tratar de um dos estados mais ricos do Brasil, o Paraná apresenta disparidades regionais consideráveis. Vidigal et al. (2012) descreve que esse desenvolvimento desequilibrado, sobretudo no que diz respeito às condições de moradia, educação, renda e infraestrutura de saúde, requer a formulação de políticas públicas que amenizem essas divergências e que possam proporcionar melhores condições de vida à população paranaense. Considerando os indicadores de condições de moradia, de precariedade dos serviços de saúde e de desenvolvimento industrial, observou-se que para cada um deles existia uma parcela de microrregiões com boas condições e outra, também de proporção significativa, com péssimos resultados. De acordo com IPARDES (2004) destacam-se nesse conjunto de microrregiões, Ponta Grossa e Paranaguá, as quais concentram boa parte da produção industrial do estado.

De acordo com Silva et al. (2006) a mesorregião Oeste Paranaense está localizada no Terceiro Planalto Paranaense e corresponde a cerca de $11,5 \%$ do território estadual. Analisando especificamente o setor rural dos municípios do oeste paranaenses, Melo (2006) aponta a existência de disparidade entre os municípios, destacando que mais de $33 \%$ encontram-se com baixos níveis de desenvolvimento rural, como reflexo dos impactos de todo o processo de modernização agrícola. De acordo com o IPARDES (2003), do ponto de vista social, a mesorregião concentra 11 dos 23 municípios nas melhores posições do estado em termos de IDH-M (Figura 1), contudo, nesta mesma mesorregião existem muitos municípios com índices entre os piores do estado, o que reflete a heterogeneidade nessa região.

Figura 2 - IDHM para os anos de 1991 e 2010

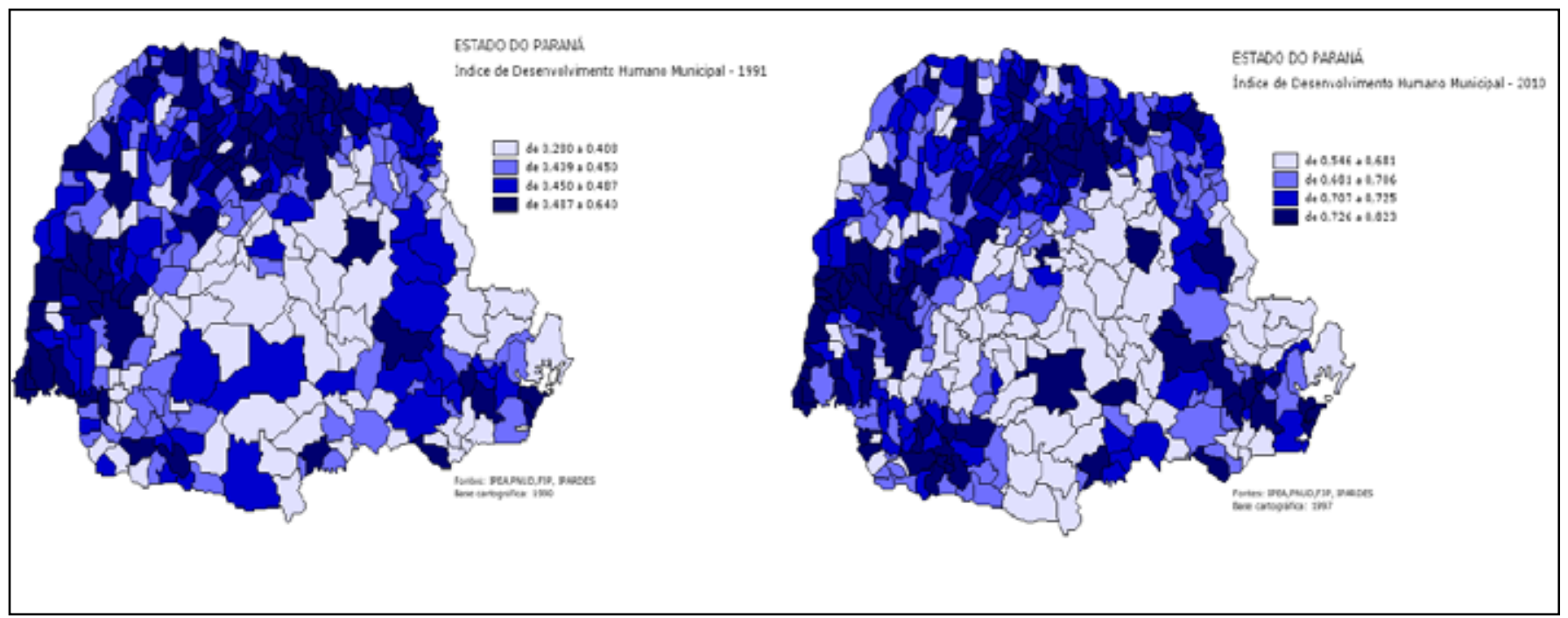

Fonte: IPARDES (2017) 
Com isso, se valida à hipótese de que o Paraná tenha mostrado melhorias socioeconômicas em 2010 em relação a 1991, mas a mudança ficou concentrada na região metropolitana de Curitiba e nas grandes cidades - é possível notar que houve concentração de renda nas grandes cidades onde a participação industrial é maior, como a região metropolitana, Norte Central e Centro Oriental - isso decorreu de uma política de incentivo ao processo de modernização produtiva e novos investimentos, sem a preocupação de desconcentração regional, já historicamente existente entre as mesorregiões do Estado (SILVA E MICHON JÚNIOR, 2008). Já ao analisar o índice de Gini (figura 3) entre 1991 e 2010 percebe-se que houve uma concentração de renda na região centro-sul e também houve desconcentração na região norte-oeste do estado.

Figura 3 - Índice de Gini para os anos de 1991 e 2010

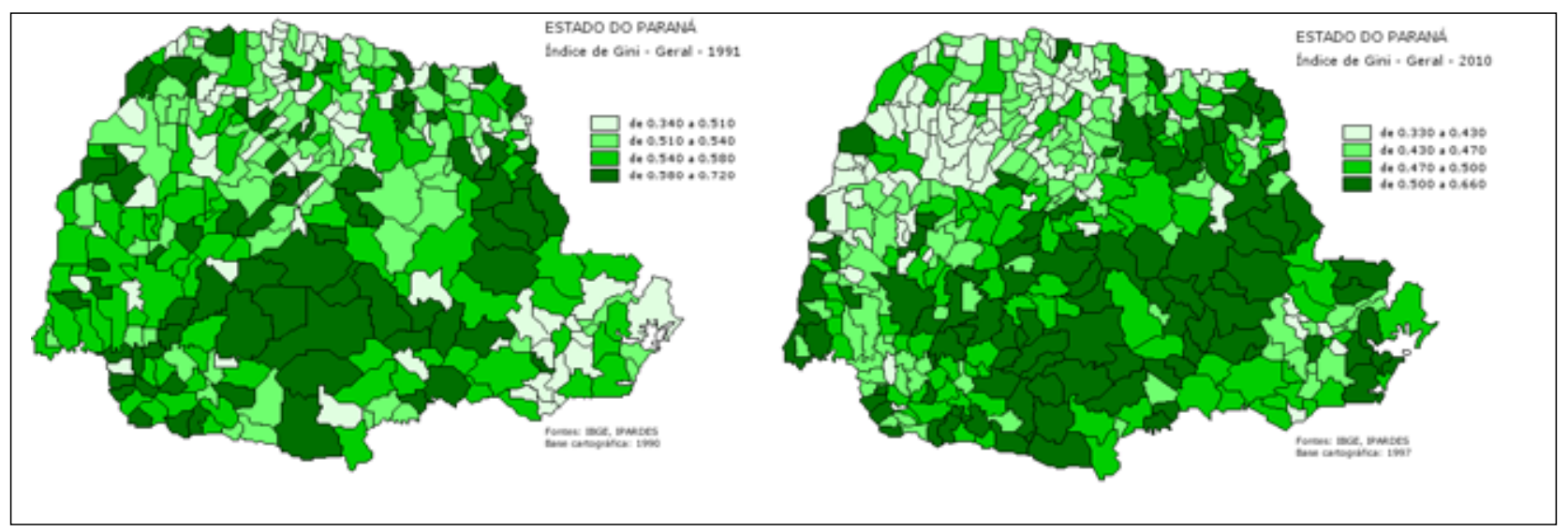

Fonte: IPARDES (2017)

Ao se investigar sobre a evolução econômica da região Norte Paranaense, Bernardelli e Sorgi (2016) descrevem que o propulsor da expansão econômica dessa região, foi o setor agropecuário, porém a consolidação econômica se deu por meio da alocação em outras atividades dos recursos providos pela agropecuária, como por exemplo, a agroindústria. Por fim, verifica-se um avanço considerável também nos municípios dessa microrregião e uma tendência positiva no que diz respeito a manter uma média dos indicadores (renda, IDH e taxa de pobreza) superiores aos do Brasil.

Se tratando da Mesorregião Norte Central Paranaense, o estudo de Teixeira (2002) considera essa região como um importante espaço econômico e social paranaense desde os anos de 1970, tendo sua economia moderna centrada nos polos de Maringá e Londrina, sendo que, atualmente, este eixo, se assemelha a região metropolitana de Curitiba, constituindo um dos maiores centros industriais e agroindustriais do Paraná. Assim, é possível verificar uma relação positiva dessa mesorregião com o IDH-M (figura 2), justificado pela mesma ser um centro agroindustrial e deter um solido setor de serviços.

Outro fato importante que colabora com os resultados apresentados sobre a mesorregião do norte central são os resultados da pesquisa de Mattei et al. (2017) que consistiu em apresentar um panorama dos municípios paranaenses a partir dos efeitos provocados pelos Arranjos Produtivos Locais (APLs) de Software e Tecnologia da Informação. Os autore concluiram que o desenvolvimento regional ocorre de forma desigual entre os 34 municípios paranaenses analisados e consequentemente entre os 6APLs de Software e Tecnologia da Informação, ocorrendo de forma mais polarizada em Curitiba, Maringá e Londrina onde os polos são maiores com melhor estrutura.

Avançando com as análises, o estudo de Lima et al. (2014) permitiu identificar e analisar o padrão de desenvolvimento municipal paranaense e a dinâmica de formação de clusters de desenvolvimento/subdesenvolvimento. O estudo identificou assimetrias a partir dos indicadores de desenvolvimento municipais paranaenses, concentrando nas mesorregiões central e leste do estado clusters de subdesenvolvimento. Assim, os autores destacam que os clusters de desenvolvimento se distribuíram basicamente em três mesorregiões: Norte Central, Oeste, e Metropolitana de Curitiba. Os clusters de subdesenvolvimento se distribuíram na região central e leste do estado. A partir das dimensões Educação e Saúde, observou-se uma forte tendência de concentração de subdesenvolvimento na região central e leste do estado do Paraná, incluindo a mesorregião Metropolitana de Curitiba. Os clusters de desenvolvimento, considerando Educação e Saúde, se concentraram predominantemente nas mesorregiões Norte Central, Noroeste e Oeste.

Como se vê, o estado apresenta desigualdades regionais consideráveis e, dessa forma, a importância da utilização da econometria espacial no estudo, e não da econometria tradicional, se dá quanto a importância da questão 
espacial inerente à economia regional. Quanto aos dados distribuídos no espaço poderem apresentar dependência ou heterogeneidade em sua estrutura, Vieira (2009) argumenta que o primeiro surge ao se questionar a independência do conjunto de dados coletados, assumindo que a proximidade intensifica o processo de conexões entre as unidades espaciais e gera concentração em determinadas localidades. A noção de proximidade, no entanto, é determinada por meio de uma ideia de espaço relativo, uma vez que a proximidade não precisa necessariamente estar relacionada à distância entre as localidades podendo ser considerados, também, distâncias econômicas, sociais e políticas. Já quanto a heterogeneidade espacial, o mesmo significa que o comportamento econômico não é estável através do espaço, e pode gerar padrões espaciais característicos sob a forma de agrupamentos ao longo do set de dados, e variar com a unidade.

No que se refere à metodologia econométrica tradicional, a presença desses efeitos pode tanto requerer alguma modificação na mesma, como pode até invalidá-la. Anselin (1988) afirma que, geralmente, essas questões são ignoradas pela teoria econométrica tradicional e formam o campo específico da Econometria Espacial. Dessa forma, fica evidente a necessidade de um modelo que capte as diferenças espaciais no estudo, uma vez observadas as diferenças regionais apresentadas pelo Paraná em seus diferentes aspectos. A próxima seção trará os procedimentos metodológicos utilizados para essa pesquisa.

\section{PROCEDIMENTOS METODOLÓGICOS}

De início, descreveu-se a Base de Dados utilizada com a Análise de Exploratória de Dados Espaciais (AEDE), posteriormente explanou-se sobre os pressupostos econométricos espaciais necessários, apresentando a matriz de pesos espaciais, os principais modelos econométricos e por fim se especificou-se o modelo econométrico espacial utilizado no presente estudo.

\section{Base de Dados}

Para o presente estudo, utilizou-se a malha georreferênciada do Paraná (shapefile) disponível no Instituto Paranaense de Desenvolvimento Econômico e Social - IPARDES. Os dados referentes às variáveis Taxa de Alfabetização, Renda Média, Índice de Gini e Urbanização utilizadas no modelo proposto foram extraídos do Censo demográfico disponível também no IPARDES para os municípios paranaenses. Para manipular os dados e incorporá-los no mapa do estado foi utilizado o software Geoda. É possível visualizar a descrição das variáveis (quanto aos seus valores médios e extremos) na tabela 3 (abaixo), onde se verifica uma alta amplitude entre os valores de todas as variáveis. Quanto a Renda Média Domiciliar per capita, se refere à média das rendas domiciliares per capita (soma dos rendimentos mensais dos moradores do domicílio, em reais, dividida pelo número de seus moradores) das pessoas residentes nos municípios.

Tabela 3 - Análise Descritiva das variáveis

\begin{tabular}{lccc}
\hline Variável & Média & Máximo & Mínimo \\
\hline Taxa de Alfabetização (\%) & 89,63 & 98,76 & 80,47 \\
Índice de Gini (\%) & 0,46 & 0,66 & 0,33 \\
Renda Média (R\$) & 600,03 & 1536,39 & 274,05 \\
Urbanização (\%) & 68,38 & 100 & 9,35 \\
\hline
\end{tabular}

Fonte: elaborado pelos autores

Já o segundo (Índice de Gini) se refere ao grau de concentração da distribuição da renda domiciliar per capita em uma determinada região geográfica, sendo que o índice varia de 0 a 1 , sendo que quando o mesmo é igual a um (1), há perfeita desigualdade de renda e quando é igual a zero (0), há perfeita igualdade. Por fim, quanto ao Grau de Urbanização, tem-se que o mesmo reflete a porcentagem populacional da área urbana em relação a população total.

\section{Econometria Espacial}

O presente estudo se utiliza do instrumental de Econometria Espacial, que é utilizada em momentos onde uma determinada variável de uma região específica influencia a mesma ou outra região próxima. A presente seção será 
composta de três partes a fim de elucidar a teoria econométrica utilizada, sendo elas: i) Matriz de Dados Espaciais; ii) Análise Exploratória de Dados Espaciais (AEDE) e; iii) Modelos Econométricos Espaciais (MEE).

\section{Matriz de Dados Espaciais}

O primeiro passo, segundo Almeida (2012) se dá na representação dos dados espaciais em uma forma matricial especificando os vizinhos de cada localidade por meio de uma matriz de pesos espaciais "” e com isso definindo um conjunto de vizinhança que interage com cada espaço geográfico. A fim de ordenar as informações seguindo os pressupostos espaciais utiliza-se, segundo Anselin (1988), o critério de contiguidade (vizinhança) refletindo a posição de uma unidade em relação às demais no espaço, sendo que os dois principais critérios são a "Rainha" e a "Torre". O primeiro considera como vizinha, uma região que possui vértices ou fronteiras em comum e a segunda somente os locais com fronteira comum. Os dados de vizinhança são representados em forma de matriz simétrica onde, que representa a relação de vizinhança entre o espaço e o espaço, assume o valor 1 se os mesmos forem vizinhos e 0 , caso contrário (pressupõe que regiões vizinhas possuam maior grau de dependência que as demais).

Por fim, Almeida (2012) destaca que existem outras maneiras de se obter uma matriz como, por exemplo, a matriz de vizinhos mais próximos, sendo a distância entre os espaços mais importante que a existência ou não de fronteiras geográficas. Sendo assim, a tarefa é determinar a matriz de pesos espaciais que melhor se ajusta a verdadeira correlação entre os dados espaciais utilizados, sendo uma forma de escolha muito utilizada analisar o valor de autocorrelação entre os dados.

\section{Análise Exploratória de Dados Espaciais (AEDE)}

Com o objetivo de se descrever e analisar a distribuição espacial, os padrões de associação espacial (clusters) e identificar os outliers, utiliza-se a AEDE, que nos fornece medidas de autocorrelação espacial global e local e a influência dos efeitos espaciais. Inicialmente, a tarefa é verificar a presença (ou não) de aleatoriedade dos dados espaciais, uma vez que se os dados forem aleatórios não haverá dependência entre os espaços e com isso não haverá sentido a utilização da econometria espacial. Para esse objetivo, verifica-se a autocorrelação espacial global e local.

Com relação à primeira, de acordo com Anselin (1988), faz-se a estatística "Índice de Moran (I)", que varia entre -1 e 1 e fornece uma medida de associação linear entre os vetores $Z t$ e a média ponderada dos valores da vizinhança (WZt), sendo a hipótese nula é de aleatoriedade espacial. O mesmo pode ser obtido pela equação abaixo, onde é o número de unidades espaciais, é o vetor de observações, é a matriz de pesos espaciais utilizada e é o somatório dos elementos da matriz de pesos espaciais .

$$
I=\left(\frac{n}{s_{0}}\right)\left(\frac{z^{\prime} W z}{z^{\prime} z}\right)
$$

Caso o valor calculado seja superior ao esperado, há autocorrelação espacial positiva, ou em outras palavras, a variável estudada apresentará valor alto (baixo) em um determinado local e, também, se observará um valor alto (baixo) dessa mesma variável em seus vizinhos. Pelo contrário, se o valor for inferior ao esperado, ter-se-á uma autocorrelação negativa.

Uma vez que a autocorrelação global pode omitir padrões do comportamento da variável em nível local que sejam estatisticamente significantes, foram criados os índices locais de autocorrelação espacial que, ainda de acordo com o autor, detectam associações espaciais diferentes por produzirem valores específicos para cada área. O principal deles é o I de Moran Local, que pode ser visto abaixo:

$$
I_{i}=\frac{\left(y_{i}-\bar{y}\right) \sum_{j} w_{i j}\left(y_{j}-\bar{y}\right)}{\sum_{i}\left(y_{j}-\bar{y}\right)}
$$

Por esse índice, se o I de Moran Local for maior que zero, há presença de clusters com valores similares ao redor de i e se for menor que zero, há clusters de valores diferentes ao redor de i (I de Moran Local igual a zero indica ausência de clusters). Outra forma de se verificar a dependência espacial, segundo Almeida (2012), é o Diagrama de Dispersão de Moran (Figura 4) onde, por meio da representação do coeficiente de regressão com valores normalizados sobre 
a média dos vizinhos, pode-se observar a correlação linear entre (variável normalizada) e (média dos vizinhos).

Figura 4 - Diagrama de Dispersão de Moran

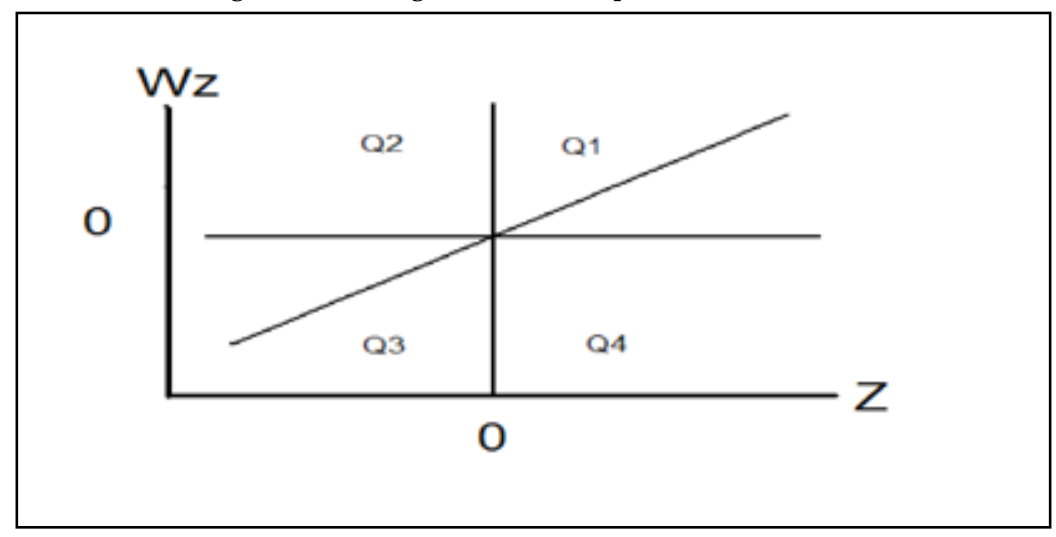

Fonte: elaborado com base em Silva (2014)

O mesmo é dividido em quatro quadrantes onde o primeiro (Q1) mostra os locais com altos valores para a variável analisada, cercadas por locais com valores acima da média para essa variável - chamado comumente de Alto-Alto (AA); já o segundo (Q2) se refere aos locais onde se verifica baixos valores na variável de análise cercados por locais com altos valores - Baixo-alto (BA); por sua vez, o terceiro quadrante (Q3) se refere aos locais onde se observa valores baixos cercado por locais de valores baixos - Baixo-baixo (BB); por fim o quarto quadrante (Q4) representa os locais com valores altos e cercados por locais com valores baixos - Alto-baixo (AB). Portanto, ainda segundo o autor, pode-se observar que os locais que estão nos quadrantes 1 e 3 apresentam associação espacial positiva formando, portanto clusters com valores similares. Já nos quadrantes 2 e 4 (com correlação negativa) tem-se a ocorrência de outliers onde não se verifica um processo de dependência espacial.

\section{Modelos Econométricos Espaciais}

Uma vez verificada a presença de dependência espacial, estimam-se os modelos econométricos que incorporam o componente espacial, que se refere a defasagens na variável dependente, defasagens na variável independente e/ ou defasagens no termo de erro. Os principais modelos econométricos espaciais (Quadro 1).

Quadro 1 - Principais Modelos Econométricos Espaciais

\begin{tabular}{|c|c|c|}
\hline Modelo & Equação & Descrição \\
\hline SAR & & $\begin{array}{c}\text { Em que é a variável dependente defasada pela matriz de pesos } \\
\text { espaciais, é o coeficiente autorregressivo espacial, que mede } \\
\text { a influência média dos vizinhos sobre a observação no vetor } \\
\text {, indicando a proporção da variação total em explicada pela } \\
\text { dependência espacial. Esse modelo não pode ser estimado por } \\
\text { MQO devido à endogeneidade do regressor, sendo estimado } \\
\text { assim por máxima verossimilhança. }\end{array}$ \\
\hline SEM & Onde & $\begin{array}{c}\text { Sendo o coeficiente o parâmetro do erro autorregressivo } \\
\text { espacial que acompanha a defasagem . Assim como } \\
\text { o modelo anterior, o SEM é estimado via máxima } \\
\text { verossimilhança. Esse modelo é apropriado quando } \\
\text { as variáveis não incluídas no modelo e presentes } \\
\text { no componente do erro são autocorrelacionados } \\
\text { espacialmente. }\end{array}$ \\
\hline
\end{tabular}

Quanto ao modelo SAR, uma das primeiras sugestões para a estimação do coeficiente é a utilização do estimador de mínimos quadrados ordinários. No entanto, quando o vetor de covariáveis (variáveis do lado direito da equação) é correlacionado com o resíduo da regressão, sabe-se que o estimador de mínimos quadrados ordinários é inconsistente. Como alternativa, pode-se utilizar estimação via máxima verossimilhança, que não sofre do problema de 
inconsistência do estimador de mínimos quadrados ordinários, devido à endogeneidade do regressor . Já quanto ao modelo SEM, note-se que, ao contrário dos modelos SAR, não apresenta a variável resposta como uma função direta dos seus lags espaciais, sendo que a autocorrelação espacial aparece nos termos de erro. Outra diferença dos modelos SEM em relação aos modelos SAR é que os coeficientes no vetor até podem ser estimados consistentemente via mínimos quadrados ordinários. O estimador de mínimos quadrados ordinários produz estimativas consistentes, mas a matriz de covariância das estimativas não será a mesma. Percebe-se que a matriz depende do coeficiente e da variância , sendo que a estimativa destes dois parâmetros pode ser obtida consistentemente a partir da estimação de um modelo SAR via máxima verossimilhança, conforme discutido no item anterior, para os resíduos.

De acordo com Anselin (1988), assim como no caso da autocorrelação temporal, a autocorrelação espacial também implica em prejuízos de estimação pelo método dos Mínimos Quadrados Ordinários (MQO), porém, de início é preciso estimar o modelo MQO para então se realizar os testes a fim de encontrar o modelo que melhor se ajusta aos dados. Os testes se dividem em duas categorias: i) testes gerais, que indicam a presença de autocorrelação, contudo não detectam qual é o tipo de autocorrelação espacial predominante e: ii) testes específicos, que indicam o tipo predominante de autocorrelação presente na regressão.

O primeiro (geral) teste utilizado, segundo Almeida (2012), é a Estatística I de Moran (adaptação do teste I de Moran) onde a hipótese nula refere-se ao fato dos resíduos da regressão por MQO serem distribuídos aleatoriamente e a rejeição da mesma sugere que os resíduos são autocorrelacionados espacialmente. Quanto aos testes específicos, em sua maioria são do tipo Multiplicador de Lagrange (ML), sendo que o Teste analisa a defasagem espacial (com hipótese nula de H0: =0) e o Teste analisa a autocorrelação espacial do termo de erro (com hipótese nula H0: ). Caso apenas um dos testes seja significante, utiliza-se este modelo em que o teste foi significante. Caso os dois testes venham a não ser significantes, o modelo não apresenta autocorrelação espacial e, portanto, o modelo tradicional é o mais apropriado. Já caso ambos sejam significantes, ter-se-á de calcular a versão robusta destes testes $\left(\mathrm{ML}^{*} \mathrm{e}\right.$ $\left.\mathrm{ML}^{\star}\right)$ e estima-se o modelo mais significante.

\section{Modelo Proposto}

Para o presente estudo o modelo a ser estimado é representador por:

$$
\text { Alfabetização }=\beta \_1+\beta \_2 \text { Gini }+\beta \_3 \text { Renda Média }+\beta \_4 \text { Urbanização }+\varepsilon
$$

Suas variáveis já foram apresentadas anteriormente e é importante destacar que a equação será estimada tanto por MQO quanto pelas técnicas de econometria espacial de modo a verificar se os efeitos espaciais são significativos para estudos sobre a alfabetização.

\section{RESULTADOS E DISCUSSÕES}

Na presente seção se apresenta a metodologia de Econometria Espacial utilizada no presente estudo. De início ter-se-á uma análise da distribuição geográfica da Taxa de Alfabetização entre os municípios paranaenses. Posteriormente se verificará a possibilidade ou não da utilização da metodologia e caso venha a ser, qual será o modelo apropriado, sendo este estimado na sequência.

\section{Resultados da Análise Exploratória dos Dados Espaciais (AEDE)}

A Figura 5 apresenta a distribuição geográfica da taxa de alfabetização nos municípios paranaenses, na qual se evidencia que as maiores escolaridades se encontram nas regiões Norte Central, Oeste, Sudeste e região Metropolitana de Curtiba, resultado esse que corrobora com as pesquisas de Silva e Michon Júnior (2008); Silva et al. (2006), Teixeira (2002) e Mattei et al. (2017).

Já os municípios onde se observa uma baixa taxa de alfabetização se encontram na região Norte Pioneiro e Centro Oriental, e na região Noroeste (de maneira mais espraiada); ainda que hajam municípios nas referidas regiões que destoem dos restantes. Este fato pode estar relacionado à distribuição da Pobreza no estado do Paraná (estudo mencionado realizado por Silva, 2014) onde se verifica uma relação positiva entre as regiões onde se encontram os municípios com menor pobreza, e as que neste estudo apresentam taxas altas de alfabetização, podendo assim a renda ser uma possível explicação para determinar a alfabetização de determinado município e/ou região. Dos 399 municípios paranaenses, destacam-se Quatro Pontes $(98,76) \mathrm{com}$ a maior taxa de alfabetização, seguido por Bom Sucesso do Sul $(98,14)$ e Curitiba $(97,87)$. Já os municípios com as menores taxas de alfabetização são Rosário do Ivaí $(80,47)$, Itaúna do Sul $(80,72)$ e Corumbataí do Sul $(80,78)$. Pela Figura 4 fica evidente que a região que apresenta 
a maior concentração de municípios com alta alfabetização do estado é a Região Metropolitana de Curitiba, área mais escura do mapa.

Analisando os dados do IPARDES (2017) é possível verificar que dentre os 20 municípios com maior taxa, 10 correspondem a somente três (Região Metropolitâna de Curitiba, Região Oeste e Região Sudeste) das dez regiões do Paraná, resultado semelhante foi encontrado no estudo de Lima et al. (2014). Na contramão, entre os 20 municípios com as menores alfabetizações têm-se que 10 destes, correspondem às regiões Norte Central e Noroeste. Uma região que merece destaque é a Norte Central, que embora tenha municípios com alta alfabetização (como é o caso de Maringá em 6⿳0 colocado) é a região a qual pertence o município de pior alfabetização do estado (Rosário do Ivaí - 80,47) reforçando a hipótese de taxas heterogêneas entre as regiões e dentro das regiões levantadas na pesquisa de Vigidal et al. (2012).

Figura 5 - Taxa de Alfabetização nos municípios do Paraná

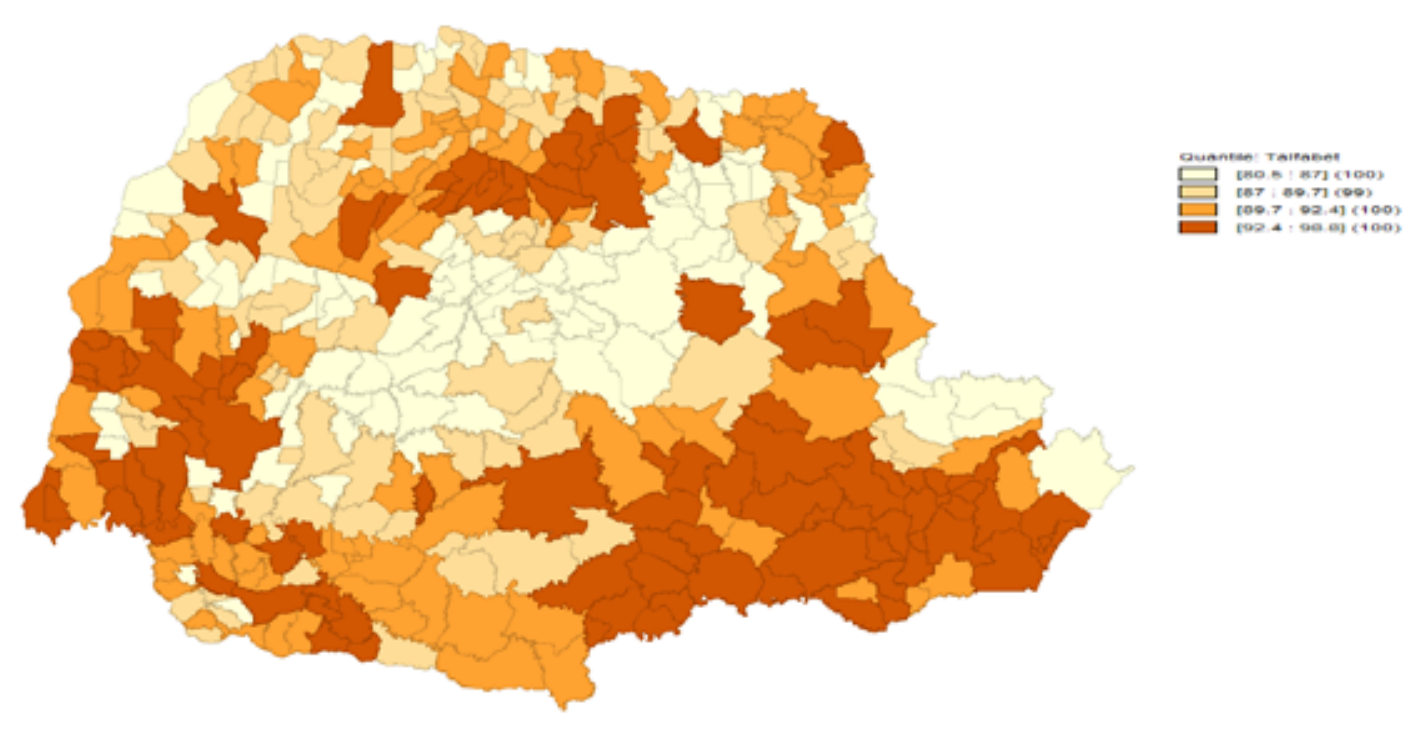

Fonte: elaborado pelos autores

\section{Índice de Moran (Global e Local)}

Com o intuito de se verificar qual matriz de pesos espaciais melhor se ajusta aos dados se calculou diferentes matrizes (Tabela 4) e analisou seus respectivos I de Moran. Destaca-se que todas as matrizes apresentaram valores positivos e significantes indicando a presença de autocorrelação espacial positiva.

Utilizou-se assim nos testes e estimação do modelo econométrico a matriz "Rainha de ordem 1", uma vez que a mesma foi a que apresentou maior I de Moran Global (0,526373).

Tabela 4 - Coeficientes do I de Moran Global para a Alfabetização no Paraná

\begin{tabular}{ccc}
\hline Matriz de Pesos Espaciais & Valor & P-valor \\
\hline Rainha de ordem 1 & 0,526373 & 0,001 \\
Torre de ordem 1 & 0,522775 & 0,001 \\
5 vizinhos mais próximos & 0,510622 & 0,001 \\
7 vizinhos mais próximos & 0,475043 & 0,001 \\
10 vizinhos mais próximos & 0,457072 & 0,001 \\
\hline
\end{tabular}

O primeiro teste (Diagrama de Dispersão do I de Moran Global) é apresentado na Figura 6 e nele se verifica que seu valor excede o valor esperado rejeitando-se, portanto, a hipótese nula de que a distribuição de Alfabetização nos municípios do Paraná é aleatória sendo assim possível o estudo espacial da variável em questão. Pode-se ob- 
servar que os municípios se encontram de maneira mais acentuada nos quadrantes 1 e 3 , ou seja, municípios com alta taxa de alfabetização são cercados por municípios também altamente alfabetizados (Q1) e municípios pouco alfabetizados são cercados por outros também com baixa taxa de alfabetização (Q3).

Figura 6 - I de Moran Global

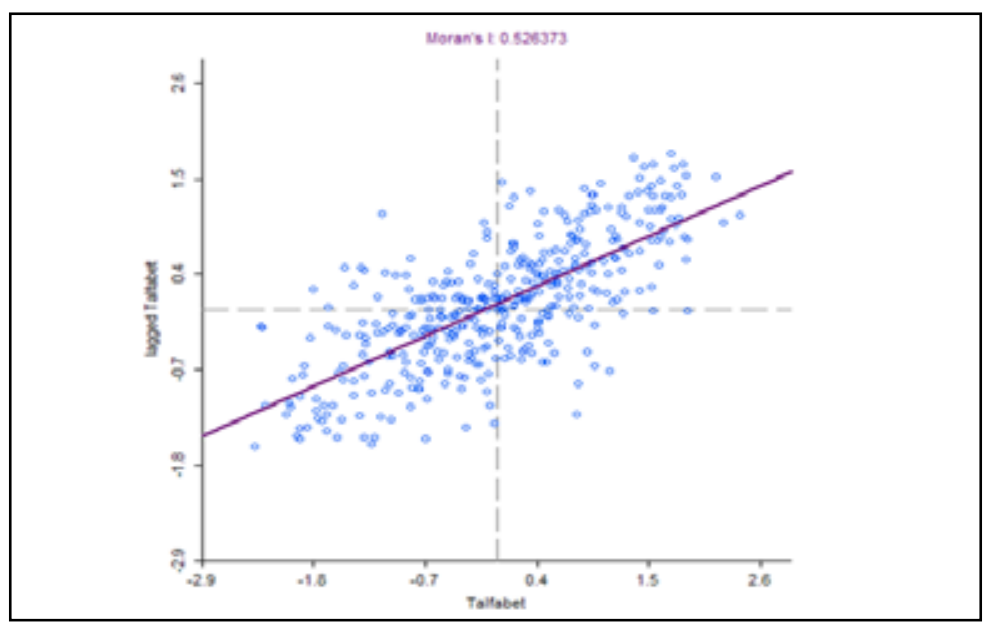

Fonte: elaborado pelos autores

Já na tabela 5 é possível visualizar o I de Moran (univariado e bivariado) das variáveis explicativas do modelo em relação à Taxa de Alfabetização.

Tabela 5 - Estatística I de Moran Global das variáveis estudadas

\begin{tabular}{lcccc}
\hline Variável & $\begin{array}{c}\text { I de Moran } \\
\text { Univariado }\end{array}$ & P-valor & $\begin{array}{c}\text { I de Moran } \\
\text { Bivariado* }^{*}\end{array}$ & P-valor \\
\hline $\begin{array}{l}\text { Taxa de } \\
\text { Alfabetização }\end{array}$ & 0,52501 & 0,001 & & \\
Renda Média & 0,279607 & 0,001 & 0,294686 & 0,001 \\
Índice de Gini & 0,311672 & 0,001 & 0,340562 & 0,001 \\
Grau de & & & & \\
Urbanização & 0,389342 & 0,001 & 0,259294 & 0,001 \\
\hline
\end{tabular}

Fonte: elaborado pelos autores

*Entre a variável dependente Taxa de Alfabetização e a variável explicativa.

Quanto ao primeiro, é possível notar uma influência espacial significativa das variáveis explicativas Renda Média, Índice de Gini e Urbanização. Quanto ao I de Moran bivariado, onde a variável dependente Taxa de Alfabetização é comparada a cada uma das variáveis independentes, é possível notar que as variáveis Renda Média e Urbanização apresentam resultados significantes e se encontram predominantemente nos quadrantes 1 e 3 sendo assim que os municípios mais alfabetizados estão cercados por municípios com altos valores de Urbanização e Renda Média, enquanto que os municípios menos alfabetizados estão rodeados por municípios com menor renda média e menos urbanizados. Com relação ao Índice de Gini é possível notar que o mesmo também é significante, o que demonstra que a concentração de renda impacta espacialmente na Taxa de Alfabetização municipal (em termos globais), porém destaca-se a relação inversa, onde os municípios mais alfabetizados estão cercados por municípios com baixos valores do Índice de Gini, enquanto que os municípios menos alfabetizados estão rodeados por municípios com altos Índice de Gini.

Com relação ao I de Moran Local na figura 7 que auxilia na localização de clusters, é possível verificar regiões de dependência espacial estatisticamente significante. 
Figura 7 - Mapa de clusters da Taxa de Alfabetização no Paraná em 2010

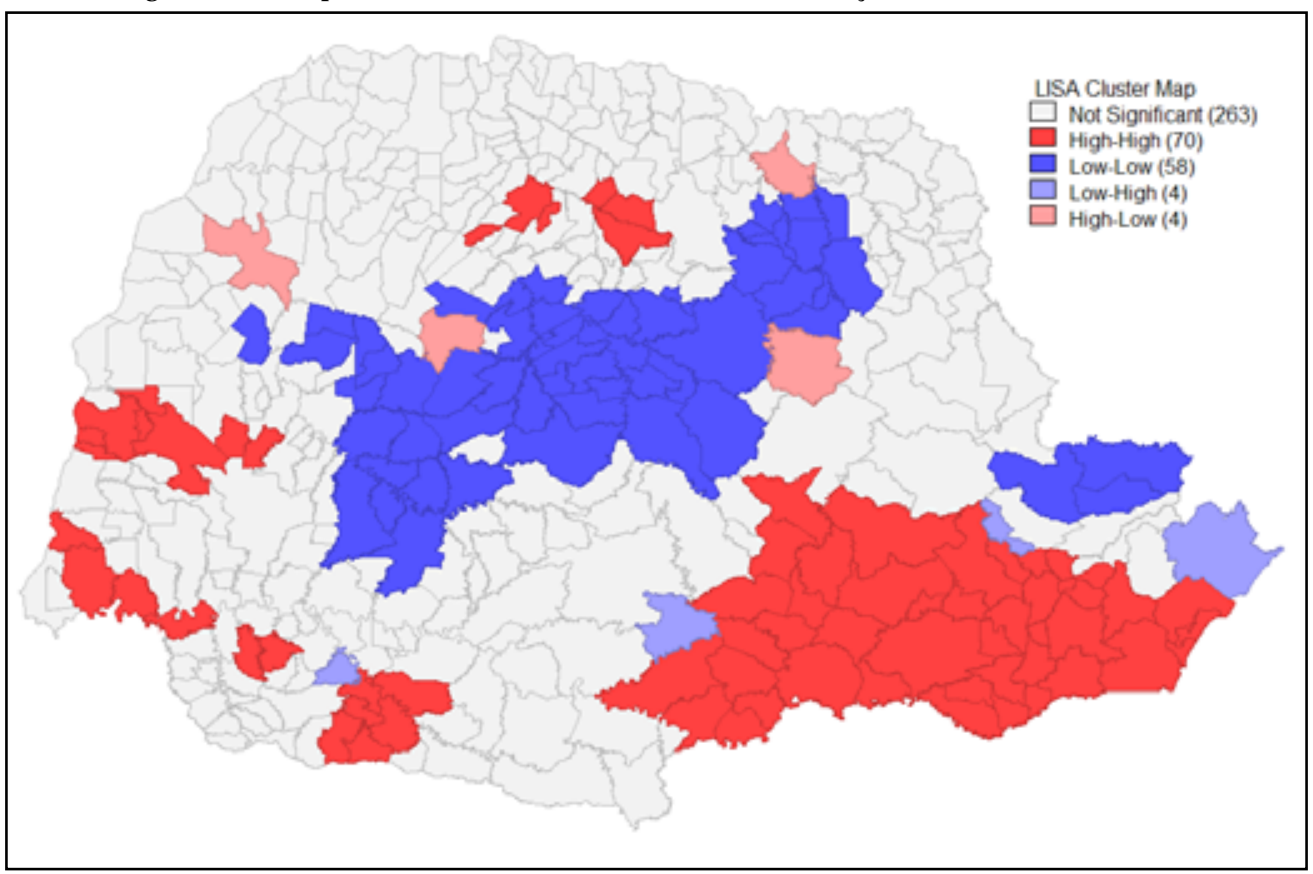

Fonte: elaborado pelos autores

Duas regiões apresentaram comportamento do tipo baixo-baixo (Q3), sendo elas a região central e região leste do Paraná que respondem por 56 municípios. Já com relação ao comportamento alto-alto (Q1) destacam-se acentuadamente as regiões sul e sudeste, e pequenos clusters nas regiões sudoeste, oeste e norte totalizando ao todo 69 municípios.

Figura 8 - Clusters bivariados entre a Taxa de Alfabetização e as variáveis explicativas

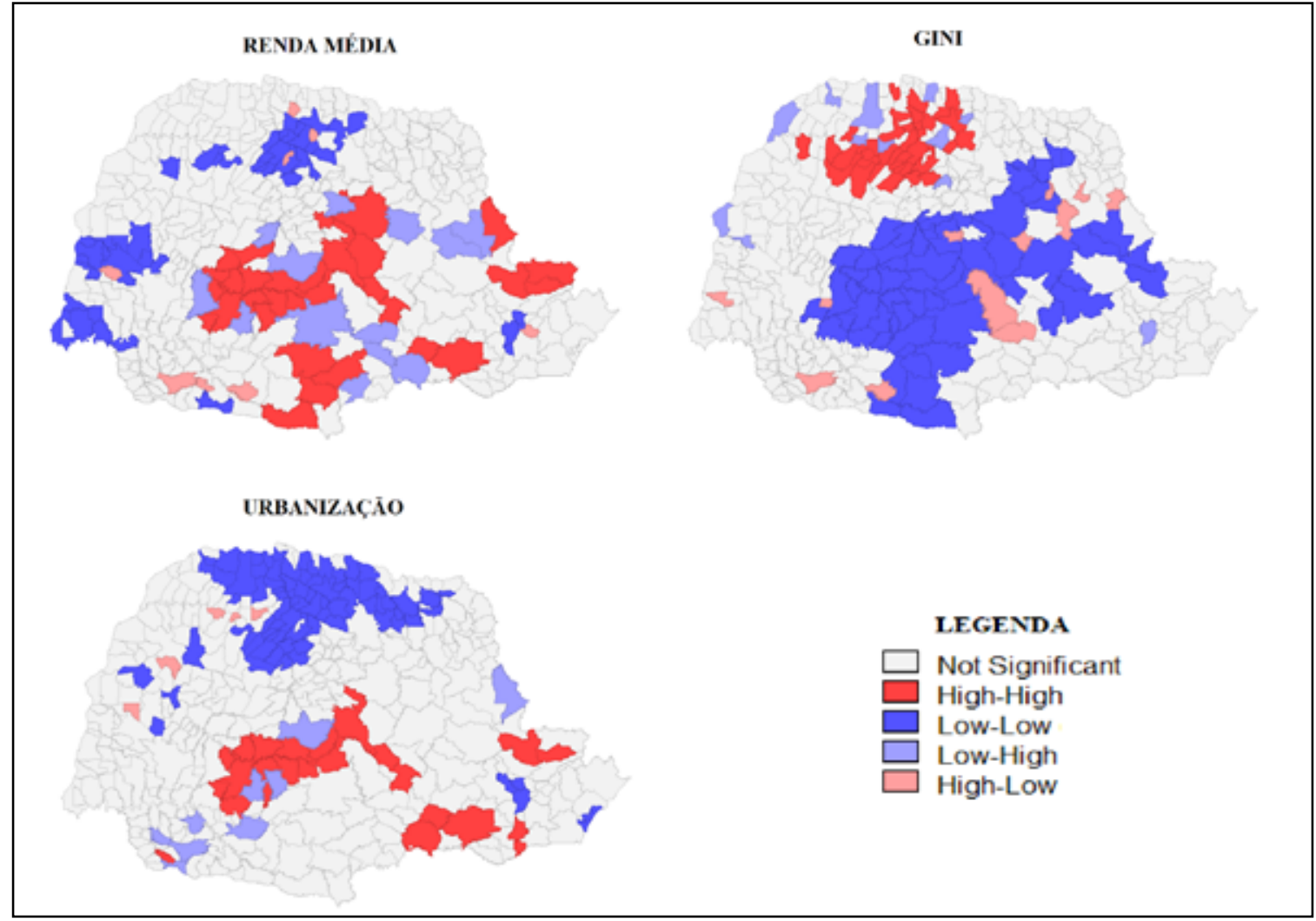

Fonte: elaborado pelos autores 
A fim de se obter uma melhor visualização do impacto espacial das variáveis independentes na taxa de alfabetização, a figura 8 (acima) apresenta o I de Moran bivariado. Com relação à ambas as variáveis, é possível identificar alguns clusters do tipo Q1 e Q3 nas mesmas regiões verificadas na variável alfabetização. Dada a concentração geográfica verificada para a taxa de alfabetização nos municípios paranaenses obtidos através de vários testes, a seguir estimar-se-á as equações de alfabetização com os métodos econométricos espaciais.

\section{Resultado do Modelo Econométrico por MQO}

A seguir (Tabela 6) encontram-se os resultados obtidos pelo método MQO tendo a variável taxa de alfabetização como dependente e as variáveis Índice de Gini, Renda Média e Urbanização como independentes. A variável Renda Média foi significativa e pode-se dizer que um aumento da mesma implica em um aumento da taxa de alfabetização. Já as variáveis Índice de Gini e Urbanização apresentaram sinal negativo, porém não foram estatisticamente significativas.

Tabela 6 - Resultados da Regressão por MQO

\begin{tabular}{lcccc}
\hline Variável & Coeficientes & Desvio-Padrão & t & p-valor \\
\hline Constante & 81,8285 & 0,6601798 & 121,2836 & 0,0000 \\
Índice de Gini & $-3,79596$ & 2,92816 & -1.29636 & 0,19561 \\
Renda Média & 0,0178054 & 0,00128557 & 13,8503 & 0,0000 \\
Urbanização & $-0,0162703$ & 0,00963096 & $-1,68937$ & 0,09194 \\
Testes & Valor & & & \\
R2 & 40,30 & & & \\
Critério Akaike & 2006,9 & & & \\
Critério Shawarz & 2022,86 & & & \\
Jarque-Bera & 0,17404 & & & \\
Breush-Pagan & 0,00025 & & & \\
\hline
\end{tabular}

Fonte: elaborado pelos autores

Como se pode ver, o teste R2 indica que as variáveis explicativas explicam $40,30 \%$ da alfabetização no Estado. O teste Jarque-Bera, que analisa a normalidade dos erros, não rejeita a hipótese de normalidade. Concluindo, ao analisar o teste Breush-Pagan (onde a hipótese nula é a presença de homocedasticidade), verifica-se ser possível rejeitar a hipótese nula com $1 \%$ de significância, apresentando, portanto, o modelo, problema de heterocedásticidade, fato este muito recorrente em estudos econométricos espaciais.

\section{Resultados do Modelo Econométrico Espacial}

Uma vez estimado o modelo por MQO, na presente seção se estimará o mesmo por métodos espaciais, sendo necessário inicialmente, como visto, detectar a presença (ou não) de autocorrelação espacial a fim de verificar qual modelo é o mais adequado. A tabela 7 (abaixo) apresenta assim os testes gerais e específicos de dependência espacial com base no modelo estimado por MQO. Uma vez verificado que os testes dos Multiplicadores de Lagrange (MLQ e ML $\lambda$ ) são estatisticamente significantes a $1 \%$ pode-se afirmar que o método dos MQO não é o mais apropriado e, consequentemente, é preciso verificar as versões robustas destes testes $\left(M^{*} \rho\right.$ e $\left.M L^{*} \lambda\right)$ e com isso escolher o modelo apropriado de acordo com a significância do mesmo. Tanto o $M L^{*} \rho$ quanto o $M L^{\star} \lambda$ foram estatisticamente significantes a $1 \%$, dessa forma estimou-se os dois modelos a fim de verificar aquele que apresenta o melhor $\mathrm{R}^{2}$, sendo este o critério de seleção para o modelo a ser empregado. 
Tabela 7 - Diagnóstico de Dependência Espacial

\begin{tabular}{lcc}
\hline Teste & Valor & Probabilidade \\
\hline$M L \lambda$ (erro) & 251,5158 & 0,00000 \\
$M L^{*} \lambda$ (erro robusto) & 24,9234 & 0,00000 \\
$M L \rho$ (defasagem) & 250,5486 & 0,00000 \\
$M L^{*} \rho$ (defasagem robusto) & 23,9562 & 0,00000 \\
\hline
\end{tabular}

Fonte: elaborado pelos autores

A Tabela 8 apresenta os resultados para ambos os modelos. Quanto ao modelo de defasagem espacial (SAR) onde se verifica que embora os coeficientes apresentam sinal condizente com o esperado, sendo o mesmo negativo para o índice de Gini e positivo para a renda média e urbanização, as variáveis Índice de Gini e Urbanização são foram estatisticamente significantes ao nível de significância de $5 \%$. O R $\mathrm{R}^{2}$ do modelo apresentou um valor de $67,32 \%$. Já quanto aos resultados para o modelo de erro espacial (SEM), se verifica que os coeficientes apresentam sinal condizente com o esperado, sendo o mesmo negativo para o índice de Gini, indicando que variações positivas no índice de Gini geram variações negativas na taxa de alfabetização, e positivo para a renda média e urbanização indicando que variações positivas em ambos tendem a resultar em variações positivas (aumento) na taxa de alfabetização. Ambos foram significantes a $5 \%$ (diferentemente do modelo anterior). Além disso, o $\mathrm{R}^{2}$ do modelo foi superior pelo método empregado $(70,84 \%)$, enquanto que persiste o problema da heterocedasticidade. Sendo assim, o impacto espacial do modelo se manifestará no termo de erro e será dado por efeitos não modelados (medida inadequada), sendo os mesmos não distribuídos aleatoriamente no espaço e sim espacialmente correlacionados.

Tabela 8 - Resultado dos modelos espaciais

\begin{tabular}{lcc|ccc}
\hline \multicolumn{1}{c}{ SAR } & & \multicolumn{3}{c}{ SEM } \\
\hline \multicolumn{1}{c}{ Variável } & Coeficientes & p-valor & Variável & Coeficientes & p-valor \\
\hline WAlfabetização & 0,650764 & & Constante & 85,8893 & 0,00000 \\
Constante & 24,3188 & 0,00000 & Índice de Gini & $-12,3355$ & 0,04438 \\
Índice de Gini & $-0,94931$ & 0,67384 & Renda Média & 0,0137618 & 0,00000 \\
Renda Média & 0,0120032 & 0,00000 & Urbanização & 0,0150214 & 0,00000 \\
Urbanização & 0,000966895 & 0,89152 & LAMBDA & 0,774062 & 0,00000 \\
Testes & Valor & & Testes & Valor & \\
R2 & 67,32 & & R2 & 70,84 & \\
Log-Likelihood & $-898,887$ & & Cog-Likelihood & $-887,223606$ & \\
Critério Akaike & 1807,77 & & Critério Shawarz & 1798,4 & \\
Critério & 1827,72 & & Breush-Pagan & 0,00047 & \\
Shawarz & & & &
\end{tabular}

Fonte: elaborado pelos autores

Sendo assim, o modelo econométrico espacial SEM se mostrou o melhor modelo para explicar socioeconomicamente a alfabetização paranaense e apresentou resultados significantes e com sinais esperados dos coeficientes, ou seja, os resultados dos modelos econométricos espaciais estão de acordo com os resultados do I de Moran bivariado. A fim de comprovar a eficácia do modelo, estimou-se o I de Moran dos resíduos, sendo que quanto mais próximo de zero ele for, melhor o modelo será. O teste (Diagrama de Dispersão do I de Moran Global) é apresentado na Figura 7 e nele se verifica que seu valor é de - 0,0646005 , confirmando, portanto, a acurácia do modelo. 
Figura 7 - I de Moran dos resíduos

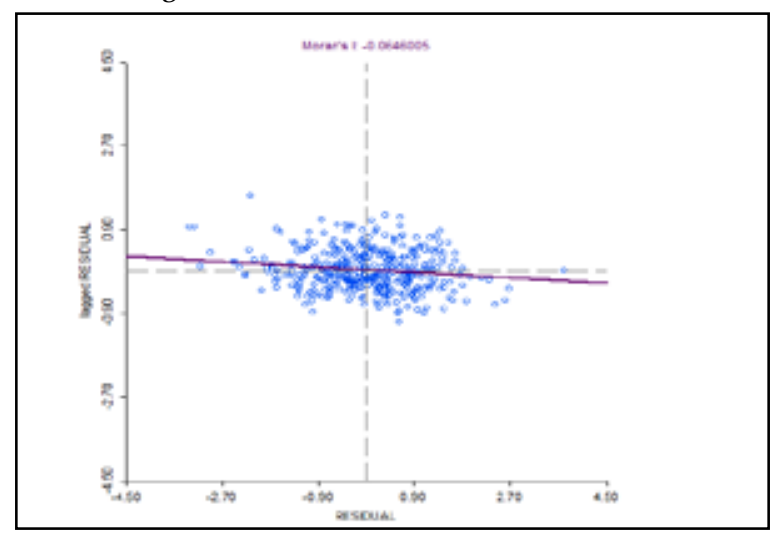

Fonte: elaborado pelos autores

Portanto, regiões com elevado índice de Gini, renda média domiciliar per capita inferior e pouca urbanização (intensivas em população rural) apresentam taxas de alfabetização menores sendo cercadas por regiões com características semelhantes e, regiões com baixos índices de Gini, renda média domiciliar per capita superior e maior urbanização (intensivas em população urbana) apresentam taxas de alfabetização maiores, sendo também cercadas por regiões com características semelhantes. O resultado corrobora com os argumentos de Cunha (1975) e Barros e Santos (2018), quanto a necessidade de condições socioeconômicas favoráveis para que exista garantia de igualdade de oportunidades.

Como destacado anteriormente em Vidigal et al (2012) e Lima et al (2014) o Paraná apresenta disparidades regionais consideráveis possuindo a partir dos indicadores de desenvolvimento municipais paranaenses clusters de subdesenvolvimento que se concentram nas mesorregiões central e leste do estado e clusters de desenvolvimento que se distribuem basicamente em três mesorregiões: Norte Central, Oeste, e Metropolitana de Curitiba. Portanto, esses clusters evidenciam os resultados obtidos demonstrando que as regiões com condições socioeconômicas adversas possuem níveis de alfabetização inferiores às demais regiões, consideradas desenvolvidas, contribuindo, portanto, para o entendimento do impacto socioeconômico na alfabetização paranaense. Com visto em Sandroni (1994) cada região depende de sua relação política de fomento a variáveis socioeconômicas importantes como: distribuição de renda, pobreza, alfabetização e outras medidas de soluções sociais, fato este que fica evidente no estudo

Os resultados vão ao encontro, tamém, do pensamento de Vidigal et al (2012) quanto a necessidade de políticas públicas que amenizem essas divergências, uma vez que, como explicitado por Schultz (1961) grande parte dos baixos rendimentos de determinados grupos de estudantes seria reflexo da falta de investimento do Estado. Pode se considerar, portanto, que políticas com o intuito de uma melhor distribuição de renda territorial são necessárias, uma vez que de acordo com os resultados as mesmas refletirão positivamente na melhora da alfabetização paranaense.

\section{Considerações Finais}

Os indicadores Índice de Gini, Renda Média e Taxa de Urbanização demonstram que há relação entre as variáveis socioeconômicas e a alfabetização, além disso, ao longo do tempo a tendência da alfabetização está se alinhando com a urbanização e essa tem ligação direta com o crescimento econômico. Segundo Sandroni (1994) o nível de vida dos cidadãos influenciado por alterações estruturais, como por exemplo, a urbanização, na economia transcende para desenvolvimento formando características de cada país ou região. Pode-se entender que uma região tem característica especifica uma vez que o desenvolvimento regional é divergente no país.

Por meio da utilização de três variáveis explicativas (Índice de Gini, Renda média e Grau de Urbanização) foi possível verificar que as mesmas estão espacialmente correlacionadas com a Taxa de Alfabetização. Este fato pode ser observado nos I de Moran bivariados e nos mapas de Clusters Bivariados onde os municípios com alta taxa de alfabetização estão cercados, preponderantemente, por municípios com baixo Índice de Gini e alto Grau de Urbanização e Renda Média, enquanto os municípios com menor alfabetização possuem vizinhos com alto índice de Gini e baixo grau de Urbanização e Renda Média.

Os resultados encontrados para a região evidenciam que os valores a partir do modelo econométrico espacial SEM se mostrou superior ao MQO para explicar socioeconomicamente a alfabetização paranaense. Os resultados reforçam as hipóteses de que municípios com baixa taxa de alfabetismo são rodeados por municípios com as mesmas características. O experimento mostrou que quanto menor o índice de Gini e maior a renda média e a urbanização, 
maior é a taxa de alfabetização nos municípios paranaenses. Sendo assim, os resultados sugerem que, quanto ao índice de Gini e a renda média per capita, pode se considerar que políticas com o intuito de uma melhor distribuição de renda territorial são necessárias, uma vez que de acordo com os resultados as mesmas refletirão positivamente na melhora da alfabetização paranaense.

\section{Referências}

ALMEIDA, E. Econometria Espacial Aplicada. Campinas: Alínea, 2012.

ANSELIN, L. Spatial Econometrics: Methods and Models. Boston: Kluwer Academic Publishers, v. 4, 1988, 284 p.

BALASSIANO, M.; SEABRA, A. A.; LEMOS, A. H. Escolaridade, salários e empregabilidade: tem razão a teoria do capital humano? Revista de Administração Contemporânea, v. 9, n. 4, p. 31-52, 2005.

BARROS, R. P. de, MENDONÇA, R., SANTOS, D. Determinantes do desempenho educacional no Brasil. TD IPEA, 2001. Disponível em: http://repositorio.ipea.gov.br/bitstream/11058/2160/1/TD_834.pdf. Acesso em: $22 / 01 / 2018$.

BARROS, R. P. de; CARVALHO, M.; FRANCO, S.; MENDONÇA, R. Consequências e causas imediatas da queda recente na desigualdade de renda brasileira. Parcerias Estratégicas, Brasília, n. 22, 2006a, p. 89-119. Edição especial: Análise sobre a pesquisa nacional por amostra de domicílios (Pnad 2004).

BARROS, R. P. de; SANTOS, D. Condições básicas para a frequência e o aprendizado do aluno. Site caminhos da aprendizagem. Disponível em: http://www.paramelhoraroaprendizado.org.br/Conteudo/verbete. aspx? canal $=20100701145550501160 \&$ subtema $=20110419135609758525 \&$ verbete $=20110419165405708125$. Acesso em: 17 de janeiro de 2018.

BECKER, G. S. Human Capital. The Concise Encyclopedia of Economics. Library of Economics and Liberty. 2008. Disponivel em: http://www.econlib.org/library/Enc/HumanCapital.html. Acesso em 18 de junho de 2015.

BERNARDELLI, L. V.; SORGI, F. A. Desenvolvimento econômico regional: uma investigação sobre a microrregião de Cornélio Procópio, Paraná (PR) para os anos de 1991 a 2012. Economia \& Região, v. 4, n. 1, p. 139-152, 2016.

CUNHA, L. A. Educação e desenvolvimento social. Rio de Janeiro: Francisco Alves, 1975.

FELÍCIO, F; FERNANDES, R. O efeito da qualidade da escola sobre o desempenho escolar: uma avaliação do ensino fundamental no estado de São Paulo. Anais do XXXIII Encontro Nacional de Economia, 2005. Disponível em: http://www.anpec.org.br/encontro2005/artigos/A05A157.pdf. Acesso em: 22/01/2018.

FOGUEL, M.; AZEVEDO, J. P. Uma decomposição da desigualdade de rendimentos de trabalho no Brasil: 1984-2005. 2006. Texto para Discussão n⿳o. 1247.

IBGE - Instituto Brasileiro de Geografia e Estatística. Taxa de analfabetismo. 2017. Disponível em http://7a12. ibge.gov.br/vamos-conhecer-o-brasil/nosso-povo/educacao.html. Acesso em 28/06/2017.

IPARDES - Instituto Paranaense de Desenvolvimento Econômico e Social. Base de dados. Curitiba. 2017.

IPARDES - Instituto Paranaense de Desenvolvimento Econômico e Social. Índice de Desenvolvimento Humano Municipal 2000: anotações sobre o desempenho do Paraná. Curitiba, 2003.

IPARDES - Instituto Paranaense de Desenvolvimento Econômico e Social. 2016. Disponível em: http://www. ipardes.gov.br/index.php?pg|_conteudo=1|\&cod \_conteudo=1. Acesso em: 29/06/2016.

IPARDES - Instituto Paranaense de Desenvolvimento Econômico e Social. Leituras Regionais: Mesorregiões geográficas do Paraná. Curitiba, 2004. 
LIMA, V. M. A.; CALDARELLI, C. E.; DA CAMARA, M. R. G. Análise do desenvolvimento municipal paranaense: uma abordagem espacial para a década de 2000. Economia e Desenvolvimento, v. 26, n. 1, 2014.

MATTEI, T. S.; DE MORAES, M. L.; BEZERRA, F. M. Os Arranjos Produtivos Locais (APLS) de Software no Paraná: Análise pela ótica do desenvolvimento regional. Economia \& Região, v. 5, n. 1, p. 125-148, 2017.

MELO, C.O. Caracterização do desenvolvimento rural dos municípios paranaenses: uma análise com base na estatística multivariada. Universidade Estadual de Maringá. Dissertação de Mestrado em Economia. Maringá, 2006.

MENEZES-FILHO, N. A.; FERNANDES, R.; PICCHETTI, P. Educação e a queda da desigualdade no Brasil. 2006b. Mimeo.

MENEZES-FILHO, N. A.; FERNANDES, R.; PICCHETTI, P. Rising human capital but constant inequality: the education composition effect in Brazil. Revista Brasileira de Economia, v. 60, p. 200-250, 2006a.

MENEZES-FILHO, N. Educação e desigualdade. In: MENEZES-FILHO, N. A.; LISBOA, M. (Eds.). Microeconomia e sociedade. Rio de Janeiro: Contracapa, 2001.

MENEZES-FILHO, N. A. Os determinantes do desempenho escolar do Brasil. IFB, 2007. Disponível em: https:// www.todospelaeducacao.org.br/arquivos/biblioteca/f4e8070a-8390-479c-a532-803bbf14993a.pdf. Acesso em: $22 / 01 / 2018$.

RAMOS, L. A desigualdade de rendimentos do trabalho no período pós-Real: o papel da escolaridade e do desemprego. Economia aplicada, v. 11, n. 2, p. 281-301, 2007.

SANDRONI, P. Dicionário de economia. São Paulo: Atlas, 1994.

SCHULTZ, T. W. Investment in human capital. American Economic Review. v. 51, n. 1, p.1-17, 1961.

SILVA, C. L. da; MICHON JUNIOR, W. Desenvolvimento socioeconômico local e reestruturação produtiva paranaense na década de 1990. Revista Interações, Campo Grande, v. 9, n. 1, p. 29-43, 2008.

SILVA, G. H. Da et al. Determinantes do Desenvolvimento Econômico e Social Dos Município da Região Oeste do Paraná: Hierarquização E Regionalização. In: 44th Congresso da Sociedade Brasileira de Economia, Administração e Sociologia Rural (SOBER), July 23-27, 2006, Fortaleza, Ceara, Brasil, 2006.

SILVA, L. N. S.; BORGES, M. J.; PARRÉ, J. L. Distribuição Espacial da Pobreza no Paraná. Revista de Economia, v. 39, n.3, p. 35-58, 2014.

TEIXEIRA, W. A. O processo de desenvolvimento geoeconômico do complexo agroindustrial cooperativista na mesorregião norte central paranaense. Tese Doutorado. Universidade do Estado de São Paulo - UNESP. 2002. Disponível em: https://repositorio.unesp.br/handle/11449/101448. Acesso em: 28/06/2017.

VIDIGAL, V. G; DE CASTRO A. I; SILVEIRA, G. F. Desenvolvimento Socioeconômico nas microrregiões do Paraná: uma análise multivariada. Revista de Economia, v. 38, n. 2, p. 51-72. 2012.

VIEIRA, E. R. A reorganização do espaço da sala de educação infantil: uma experiência concreta à luz da Teoria Histórico-Cultural. Dissertação de Mestrado (UNESP - campus de Marília). Marília, 2009. 